\title{
Systemic Lupus Erythematosus Complicated with Hypertrophic Cardiomyopathy: A Case Report and Literature Review
}

\author{
Huihui Ma $\mathbb{D}^{1,2}$ Xin Cao $\mathbb{D}^{3}{ }^{3}$ Jing Zhang $\mathbb{D},{ }^{1,2}$ Yongmei Zhou $\mathbb{D}^{1,2}$ Rong Luo $\mathbb{D}^{4}{ }^{4}$ Tao He $\mathbb{D}^{1,2}$ \\ Jianhong Tao $\mathbb{D},^{1,2}$ and Xiaoping $\mathrm{Li} \mathbb{D}^{1,2}$ \\ ${ }^{1}$ Department of Cardiology, Sichuan Provincial People's Hospital, University of Electronic Science and Technology of China, Chengdu, \\ Sichuan 610072, China \\ ${ }^{2}$ Chinese Academy of Sciences Sichuan Translational Medicine Research Hospital, Chengdu 610072, China \\ ${ }^{3}$ Chengdu University of Traditional Chinese Medicine, Chengdu, Sichuan 610075, China \\ ${ }^{4}$ Institute of Geriatric Cardiovascular Disease, Chengdu Medical College, Chengdu, Sichuan 610500, China
}

Correspondence should be addressed to Xiaoping Li; lixiaoping0119@163.com

Received 16 November 2020; Accepted 30 March 2021; Published 12 April 2021

Academic Editor: Ertugrul Ercan

Copyright (C) 2021 Huihui Ma et al. This is an open access article distributed under the Creative Commons Attribution License, which permits unrestricted use, distribution, and reproduction in any medium, provided the original work is properly cited.

A 32-year-old female with systemic lupus erythematosus (SLE) for more than 7 years, and long-term treatment with cyclophosphamide, cyclosporine, methotrexate, and tacrolimus, later found to be combined with hypertrophic cardiomyopathy (HCM) for one year. The patient denied a family history of cardiomyopathy and sudden cardiac death (SCD). Echocardiography suggested that uneven thickening of the left ventricle (LV), mainly in the lower middle segment. Cardiac magnetic resonance (CMR) showed that the walls of the left ventricular (LV) were significantly thickened, as about $21 \mathrm{~mm}$, mainly in the middle and lower segments. Genetic tests showed no known or suspected pathogenic variations were found and no significant enhancement in CMR, so secondary HCM was diagnosed clinically. After symptomatic treatment, the patient was discharged, and long-term follow-up was conducted. The diagnosis of HCM, which combined with SLE or second to usage of tacrolimus, was based on symptoms, echocardiography, and CMR; no endomyocardial biopsies were performed.

\section{Introduction}

Hypertrophic cardiomyopathy (HCM) is a disease characterized by cardiac hypertrophy, which is usually manifested as left ventricular hypertrophy $[1,2]$. HCM can be diagnosed by left ventricular wall or septal thickness $\geq 15 \mathrm{~mm}$ measured by two-dimensional echocardiography or $\geq 13 \mathrm{~mm}$ in patients with a definite family history [1-4]. Systemic lupus erythematosus (SLE) is an autoimmune disease, and the etiology is not completely clear. It is characterized by autoantibodies and immune complexes, which can cause multiple system damage [5]. Cardiovascular system is one of the most frequently involved systems, and cardiovascular events are also an important cause of death in lupus patients [6-12]. Up to $9 \%$ of patients with SLE are reported to have cardiac manifestations, including myocarditis, cardiomyopathy $(\mathrm{CM})$, and/or heart failure (HF) [13]. Whether there is car- diomyopathy directly caused by lupus is not clear [13]. We present the 10th case of HCM associated with SLE and discuss the possible causes of cardiac hypertrophy in this patient.

\section{Clinical Data}

2.1. Case Report. A 32-year-old female was admitted to the emergency department for 6-day history of fever accompanied by abdominal pain and diarrhea. The highest body temperature was about $39.4^{\circ} \mathrm{C}$, with obvious chill and Raynaud's phenomenon. The local clinic provided anti-inflammatory, antiviral, and antipyretic treatments such as "Cephalosporins, Ribavirin and Lysine Acetylsalicylate", but the body temperature was not significantly decreased. After that, the patient continued to have fever; the body temperature was monitored at 37.8$38.5^{\circ} \mathrm{C}$, so she was admitted to our emergency department. 


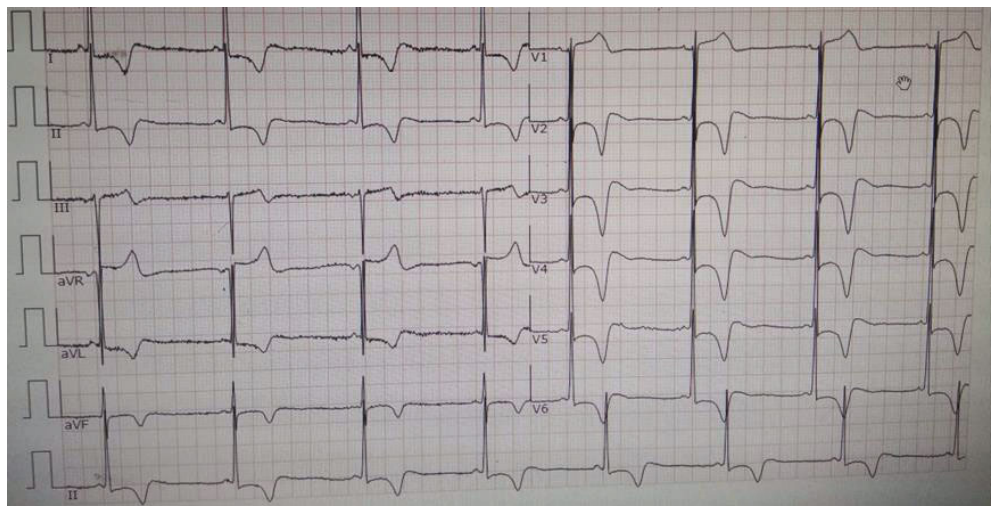

FiguRE 1: Electrocardiogram showing significant sinus bradycardia, with normal electric axis, short PR interval, high left ventricular voltage, and ST-T change; V2-V6 leads T-wave inversion.

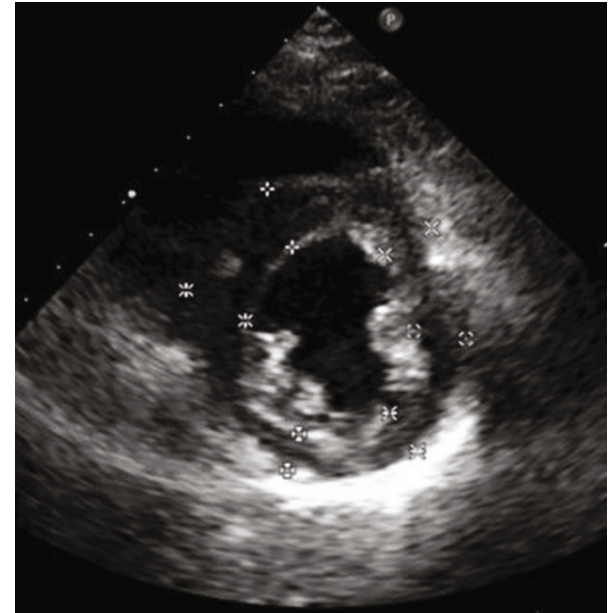

FIGURE 2: Echocardiography showing the thickened walls in the middle and lower segments.

The patient was diagnosed with SLE for more than 7 years. After that, she was hospitalized in our hospital for several times due to recurrent fever accompanied by abdominal pain, diarrhea, nausea, vomiting, etc., and received anti-infection and immune regulation treatment (long-term use of cyclophosphamide, cyclosporine, methotrexate, and tacrolimus).

2.2. Physical and Laboratory Examination. After admission, the patient presented with Cushing's syndrome. Bone friction was positive, and there was no cardiac murmur.

Laboratory evaluations revealed the following: leukocyte count was $7.160 \times 10^{9} / \mathrm{L}$, neutrophil count was $6.480 \times 10^{9}$ $/ \mathrm{L}$, platelet count was $188 \times 10^{9} / \mathrm{L}$, and hemoglobin level was $131 \mathrm{~g} / \mathrm{L}$. Brain natriuretic peptide (BNP) was $752 \mathrm{pg} / \mathrm{mL}$. Procalcitonin was $0.08 \mathrm{ng} / \mathrm{mL}$. Erythrocyte sedimentation rate was $27 \mathrm{~mm} / \mathrm{h}$. Carbohydrate antigen 19-9 (CA19-9) was $63.86 \mathrm{U} / \mathrm{nL}$. Complement C3 was $0.313 \mathrm{~g} / \mathrm{L}$; complement $\mathrm{C} 4$ was $0.078 \mathrm{~g} / \mathrm{L}$. The results of anti-Nrnp/Sm antibody, anti-dsDNA antibody, and anti-nucleosome antibody (ANUA) were all positive $(+++)$. Anti-histone antibody (AHA) was also postive $(++)$, and meanwhile, antiribosome $\mathrm{P}$-protein antibody (ARPA) and anti-nuclear anti-

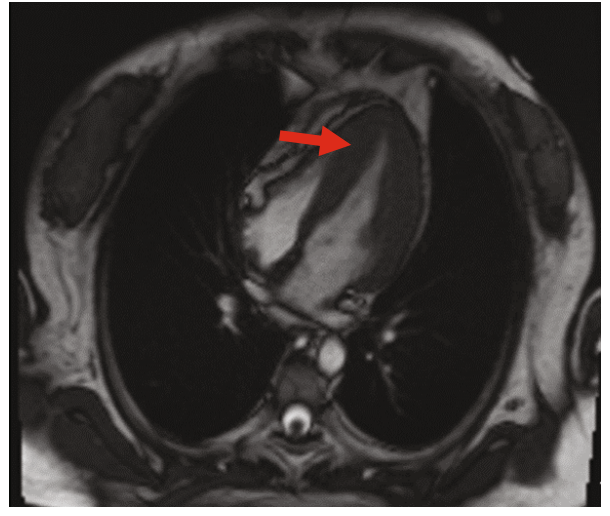

Figure 3: Cardiac magnetic resonance showing the walls of the left ventricle were significantly thickened, mainly in the middle and lower segments (T2-weighted image).

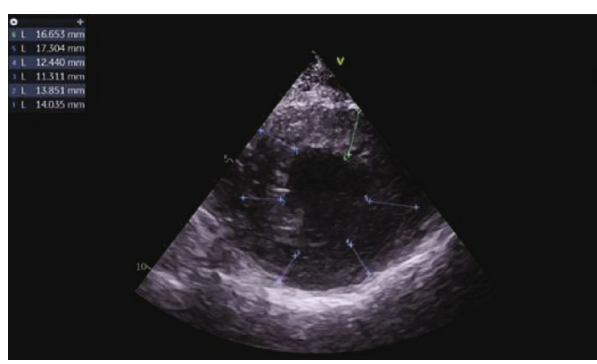

Figure 4: Echocardiography on reexamination showing little thickening of the left ventricular wall.

body (ANA) were postive (+), too. Nuclear homogeneous type was $1: 3200$, and nuclear particle type was $1: 1000$.

2.3. Electrocardiogram. The electrocardiogram of the patient showed significant sinus bradycardia, with normal electrical axis, short PR interval, high left ventricular voltage, and STT change. V2-V6 leads T-wave inversion (Figure 1).

2.4. Echocardiography. The echocardiography showed left ventricular diastolic dysfunction, and the left ventricular ejection fraction (LVEF) of the heart was $67 \%$. The cardiac 


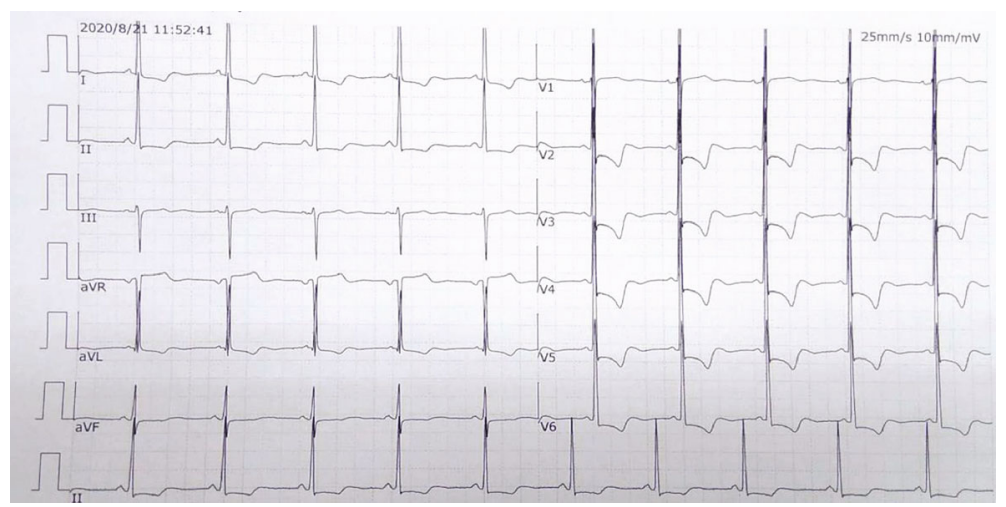

FIGURE 5: Electrocardiogram on reexamination showing sinus rhythm; T-wave inversion was significantly improved than before.

diameter was normal (left atrial, $\mathrm{LA}=25 \mathrm{~mm}$; left ventricle, $\mathrm{LV}=45 \mathrm{~mm}$; right ventricle, $\mathrm{RV}=18 \mathrm{~mm}$; right atrial, $\mathrm{RA}$ $=34 \times 27 \mathrm{~mm})$. The left ventricular myocardium was unevenly thickened, especially in the middle and lower segments up to $15 \mathrm{~mm}$. Left ventricular diastolic function decreased, $E / A=0.9$. Systolic anterior motion (SAM) syndrome was slightly positive. The systolic and diastolic pulmonary blood pressures were about $24 \mathrm{mmHg}$ and $11 \mathrm{mmHg}$, respectively, with an average of about $16 \mathrm{mmHg}$ (Figure 2).

2.5. CMR. CMR confirmed left ventricular diastolic dysfunction. The walls of the left ventricle were significantly thickened, mainly in the middle and lower segments. The diastolic period thickness was about $21 \mathrm{~mm}$. There was no obstruction in the LVOT and late gadolinium enhancement (LGE) of the myocardial wall. No obvious thickening of the pericardium and effusion was found. On the basis of these data, HCM was diagnosed (Figure 3).

\section{Genetic Testing}

To exclude primary HCM, we used a blood DNA extraction kit to extract genomic DNA from peripheral blood samples. We targeted and enriched for the exons and neighboring introns (within $50 \mathrm{bp}$ ) of the 130 genes associated with cardiomyopathy. Based on the guideline for the interpretation of sequence variants: a joint consensus recommendation of the American College of Medical Genetics and Genomics and the Association for Molecular Pathology [14], no known or suspected pathogenic variants consistent with the phenotype were found.

\section{Outcome and Follow-Up}

At a follow-up visit in August 2020, the patient described occasional chest tightness, but the symptoms were not apparent, and the drug was not taken. Echocardiography showed no significant change in ventricular wall thickness from that recorded 1 year earlier (Figure 4), but ECG showed that the T-wave inversion of the V2-V6 leads improved (Figure 5).

\section{Discussion}

We have described a patient with SLE in combination with HCM. The patient had a 7-year history of SLE but no history of myocardial hypertrophy in the previous 6 years. Only nine cases of SLE with HCM have been described, and the underlying mechanisms linking them, if present, are unknown. Therefore, we investigated whether our patient had SLE coincident with primary HCM or HCM secondary to SLE, drug treatment, or unknown cause.

The majority of HCM cases are caused by gene mutations, but it can also occur secondary to other diseases or to long-term use of certain drugs, such as anabolic steroids, tacrolimus, and hydroxychloroquine [15-17]. SLE is a multisystem connective tissue disease that can affect all organs of the body. More than $50 \%$ of SLE patients have cardiac involvement, and lesions can involve the pericardium, myocardium, endocardium, valve, conduction system, and coronary arteries [8]. The pericardium is commonly the first site to be involved and occurs in $11 \%-54 \%$ of cases according to electrocardiographic studies [9]. Autopsy findings suggest that about $62 \%$ of SLE patients have pericardium involvement [10]. Myocarditis is the most typical feature of myocardial involvement in SLE, and it can progress to ventricular dysfunction, dilated cardiomyopathy (DCM), and $\operatorname{HF}[11,12]$. Coronary heart disease (CAD) is the most common cause of death in patients with late-onset or long-term SLE [11-13].

The patient described here had received a diagnosis of SLE 7 years before presentation, but she had no family history of HCM or SCD and denied a history of hypertension. Echocardiography and CMR imaging supported a diagnosis of nonobstructive HCM. To exclude idiopathic HCM, we performed next-generation sequencing and analysis with a focus on 130 genes known to be associated with cardiomyopathy. The patient had no known or suspected pathogenic variants consistent with the phenotype, which exclude mostly idiopathic cardiomyopathy and instead suggested HCM secondary to another cause(s).

As noted, the cardiovascular system is commonly involved in SLE [9-12], which initially suggested that SLE may have been the direct cause of HCM. However, HCM has not been clearly linked to SLE to date, and cases of SLE 
TABLE 1: Case report about patients with SLE and HCM.

\begin{tabular}{|c|c|c|c|c|c|c|}
\hline Cases & $\begin{array}{c}\text { Age } \\
\text { (years) }\end{array}$ & Gender & Symptom & Drugs & $\begin{array}{c}\text { Diagnostic } \\
\text { methods }(\mathrm{HCM})\end{array}$ & References \\
\hline $\begin{array}{l}\text { Asherson et al., } \\
1992\end{array}$ & 51 & Female & Palpitations, chest pain & $\begin{array}{l}\text { Steroids, immunosuppressant, } \\
\text { warfarin, antidepressant }\end{array}$ & Echocardiography & {$[18]$} \\
\hline $\begin{array}{l}\text { Asherson et al., } \\
1992\end{array}$ & 45 & Female & Palpitations, dyspnea & $\begin{array}{l}\text { Propranolol, mexiletine, } \\
\text { digoxin, amiodarone }\end{array}$ & Echocardiography & {$[18]$} \\
\hline Ara et al., 1998 & 45 & Female & $\begin{array}{l}\text { Intermittent palpitations, } \\
\text { grade II dyspnea, } \\
\text { orthopnoea }\end{array}$ & Hydroxychloroquine & Echocardiography & [19] \\
\hline $\begin{array}{l}\text { Dongji and } \\
\text { Yuan, } 1998\end{array}$ & 35 & Female & Chest distress, syncope & $\begin{array}{l}\text { Hormone, } \beta \text {-blocker, } \\
\text { calcium antagonist }\end{array}$ & Echocardiography & {$[20]$} \\
\hline $\begin{array}{l}\text { Anastasiadis } \\
\text { et al., } 2001\end{array}$ & 32 & Female & $\begin{array}{c}\text { Arthralgias, malar rush, } \\
\text { intermittent palpitations } \\
\text { membranoproliferative } \\
\text { nephritis }\end{array}$ & $\mathrm{N}$ & Echocardiography & {$[21]$} \\
\hline $\begin{array}{l}\text { Anastasiadis } \\
\text { et al., } 2001\end{array}$ & 37 & Female & $\begin{array}{l}\text { Physical and laboratory } \\
\text { findings similar to those } \\
\text { found in case } 1\end{array}$ & $\mathrm{~N}$ & Echocardiography & {$[21]$} \\
\hline $\begin{array}{l}\text { Anastasiadis } \\
\text { et al., } 2001\end{array}$ & 19 & Male & $\begin{array}{l}\text { Liver failure due to } \\
\text { Budd-Chiari syndrome } \\
\text { antiphospholipid } \\
\text { syndrome }\end{array}$ & $\mathrm{N}$ & Echocardiography & {$[21]$} \\
\hline $\begin{array}{l}\text { Maezawa } \\
\text { Linghua, } 2002\end{array}$ & 23 & Female & Palpitations & Steroid & & {$[22]$} \\
\hline $\begin{array}{l}\text { Kotani et al., } \\
2005\end{array}$ & 37 & Female & $\begin{array}{l}\text { Exertional chest pain } \\
\text { nephrotic syndrome }\end{array}$ & $\begin{array}{l}\text { Prednisolone, cyclophosphamide, } \\
\text { mizoribine, } \beta \text {-blocker }\end{array}$ & $\begin{array}{l}\text { Echocardiography, } \\
\text { pathological biopsy }\end{array}$ & {$[23]$} \\
\hline $\begin{array}{l}\text { The present } \\
\text { study }\end{array}$ & 32 & Female & $\begin{array}{l}\text { Fever accompanied by } \\
\text { abdominal pain } \\
\text { and diarrhea }\end{array}$ & $\begin{array}{l}\text { Cyclophosphamide, cyclosporin, } \\
\text { methotrexate tacrolimus }\end{array}$ & $\begin{array}{l}\text { Echocardiography, } \\
\text { CMR }\end{array}$ & \\
\hline
\end{tabular}

$\mathrm{N}$ : not mentioned in the article; CMR: cardiac magnetic resonance.

complicated with HCM are rare (Table 1) [18-23]. Among the nine reported cases, eight $(89 \%)$ were female, and two reported a family history of $\operatorname{SCD}(n=1)$ and $\operatorname{HCM}(n=1)$ $[18,20]$. As shown in Table 1 , the patients were relatively young (mean age $36.0 \pm 10.4$ years) and had a history of systemic disease for many years. HCM was mainly diagnosed by echocardiography, with only one patient undergoing echocardiography and pathological biopsy [23]. The findings of the present study are similar to the previously reported cases. Of note, both SLE and SLE with HCM predominantly affect women.

We considered whether our patient's long-term use of medications such as tacrolimus might be the cause of HCM, especially because her echocardiography and ECG were normal prior to 2019. Diffuse thickening is a key characteristic of drug-induced cardiomyopathy, but it can also manifest as heterogeneous thickening [17, 24], as may have been the case with our patient. Tacrolimus is an effective immunosuppressant most commonly used in patients with kidney, liver, or heart transplants [25]. However, tacrolimus has been reported to have toxic side effects, including cardiotoxicity $[17,26]$. Tacrolimusinduced HCM has been described mainly, but not exclusively, in children $[11,27,28]$. And the change is reversible [17]. During follow-up, the patient studied here ceased to take tacrolimus, and although echocardiography showed no significant change in wall thickness, the Twave inversion of the ECG leads was improved. The patient had no family history of hypertension, HCM, or other cardiovascular disease. Taking these observations into account, we suspected that HCM in our patient was most likely caused by tacrolimus. However, longer follow-up may be needed to prove it.

The goal of this report is to provide further information about the clinical presentation of SLE with HCM and to provide some clues for the study of the relationship between them. Although the concomitant occurrence of the two pathologies may be purely coincidental, advances in molecular biology techniques may shed light on the direct underlying mechanisms linking SLE and HCM.

\section{Conclusion}

To the best of our knowledge, our patient is the 10th reported case of SLE combined with HCM. The specific mechanism linking SLE and HCM is not yet clear, but a significant gender bias is present, with $89 \%$ of the reported cases being female. Patients with SLE should be cautioned about the potential for cardiovascular complications. 


\section{Data Availability}

Data are available from the authors upon request. The data that support the findings of this study are available from the corresponding author (Xiaoping Li. E-mail: lixiaoping0119@163.com) upon request.

\section{Conflicts of Interest}

The authors declare that they have no conflict of interest.

\section{Authors' Contributions}

Huihui Ma, Jing Zhang, Yongmei Zhou, and Rong Luo collected previous study of systemic lupus erythematosus (SLE) and hypertrophic cardiomyopathy (HCM). Xiaoping $\mathrm{Li}$, Xin Cao, Tao He, and Jianhong Tao conceived and designed the study. Huihui Ma wrote the paper. All authors read and approved the manuscript.

\section{Acknowledgments}

This work was supported by the National Natural Science Foundation of China (No. 81770379, No. 81500297, and No. 81470521).

\section{References}

[1] Chinese Society of Cardiology, Chinese adult hypertrophic cardiomyopathy diagnosis and treatment guidelines preparation group, Editorial Board of Chinese Journal of Cardiology, "Guidelines for the diagnosis and treatment for Chinese adult patients with hypertrophic cardiomyopathy," Chinese Journal of Cardiology, vol. 45, no. 12, pp. 1015-1032, 2017.

[2] C. M. Wolf, "Hypertrophic cardiomyopathy: genetics and clinical perspectives," Cardiovascular diagnosis and therapy, vol. 9, no. S2, pp. S388-S415, 2019.

[3] B. J. Maron, "Clinical course and management of hypertrophic cardiomyopathy," The New England Journal of Medicine, vol. 379, no. 7, pp. 655-668, 2018.

[4] M. Shah, "Hypertrophic cardiomyopathy," Cardiology in the Young, vol. 27, no. S1, pp. S25-S30, 2017.

[5] K. Oku and T. Atsumi, "Systemic lupus erythematosus: nothing stale her infinite variety," Modern Rheumatology, vol. 28, no. 5, pp. 758-765, 2018.

[6] A. I. Diadyk, G. G. Taradin, A. E. Bagriǔ, N. F. Iarovaia, and T. V. Taradina, "Cardiac involvement in systemic lupus erythematosus [J]," Mayo Clinic Proceedings, vol. 74, no. 3, pp. 275-284, 1999.

[7] J. Chen, Y. Tang, M. Zhu, and A. Xu, "Heart involvement in systemic lupus erythematosus: a systemic review and metaanalysis," Clinical Rheumatology, vol. 35 , no. 10, pp. 24372448, 2016.

[8] K. Tselios and M. B. Urowitz, "Cardiovascular and pulmonary manifestations of systemic lupus erythematosus," Current Rheumatology Reviews, vol. 13, no. 3, pp. 206-218, 2017.

[9] N. E. Doherty and R. J. Siegel, "Cardiovascular manifestations of systemic lupus erythematosus," American Heart Journal, vol. 110, no. 6, pp. 1257-1265, 1985.
[10] A. Doria, L. Iaccarino, P. Sarzi-Puttini, F. Atzeni, M. Turriel, and M. Petri, "Cardiac involvement in systemic lupus erythematosus," Lupus, vol. 14, no. 9, pp. 683-686, 2005.

[11] C. Usalan, H. Buyukhatipoglu, and O. Tiryaki, "Systemic lupus erythematosus complicated by dilated cardiomyopathy and severe heart failure," Clinical Rheumatology, vol. 26, no. 1, pp. 125-127, 2007.

[12] J. J. Miner and A. H. Kim, "Cardiac manifestations of systemic lupus erythematosus," Rheumatic Diseases Clinics of North America, vol. 40, no. 1, pp. 51-60, 2014.

[13] M. L. Ishimori, M. Agarwal, R. Beigel et al., "Systemic lupus erythematosus cardiomyopathy-a case series demonstrating a reversible form of left ventricular dysfunction," Echocardiography, vol. 31, no. 5, pp. 563-568, 2014.

[14] on behalf of the ACMG Laboratory Quality Assurance Committee, S. Richards, N. Aziz et al., "Standards and guidelines for the interpretation of sequence variants: a joint consensus recommendation of the American College of Medical Genetics and Genomics and the Association for Molecular Pathology," Genetics in Medicine, vol. 17, no. 5, pp. 405-423, 2015.

[15] E. Joyce, A. Fabre, and N. Mahon, "Hydroxychloroquine cardiotoxicity presenting as a rapidly evolving biventricular cardiomyopathy: key diagnostic features and literature review," European Heart Journal Acute Cardiovascular Care, vol. 2, no. 1, pp. 77-83, 2013.

[16] A. Frustaci, E. Morgante, D. Antuzzi, M. A. Russo, and C. Chimenti, "Inhibition of cardiomyocyte lysosomal activity in hydroxychloroquine cardiomyopathy," International Journal of Cardiology, vol. 157, no. 1, pp. 117-119, 2012.

[17] K. Noda, T. Ukichi, K. Furuya et al., "Tacrolimus-induced hypertrophic cardiomyopathy in a patient with dermatomyositis," Rheumatology (Oxford, England), vol. 56, no. 11, pp. 2037-2038, 2017.

[18] R. A. Asherson, D. Ames, J. Coltart, C. Byrne, and G. R. Hughes, "Hypertrophic cardiomyopathy in systemic lupus erythematosus and "lupus-like" disease. Chance association? A report of 2 cases," The Journal of Rheumatology, vol. 19, no. 12, pp. 1973-1977, 1992.

[19] J. Ara, J. Vivancos, J. Soler-Carrillo, J. C. Paré, R. Cervera, and J. Font, "Hypertrophic cardiomyopathy and systemic lupus erythematosus," Clinical Rheumatology, vol. 17, no. 6, pp. 531-533, 1998.

[20] D. An and F. Yuan, "A case of systemic lupus erythematosus with hypertrophic obstructive cardiomyopathy [J]," Journal of Clinical Internal Medicine, vol. 3, p. 144, 1998.

[21] G. P. Anastasiadis, I. Moyssakis, K. Boki, and M. Kyriakidis, "Hypertrophic cardiomyopathy in systemic lupus erythematosus," Mayo Clinic Proceedings, vol. 76, no. 1, p. 111, 2001.

[22] M. Linghua, "Systemic lupus erythematosus with hypertrophic cardiomyopathy improved by steroid therapy: a case report [J]," Kanto rheumatism, vol. 36, pp. 77-86, 2002.

[23] T. KOTANI, T. TAKEUCHI, M. SAKAMOTO et al., "A case of systemic lupus erythematosus associated with hypertrophic cardiomyopathy," Nihon Rinshō Men'eki Gakkai Kaishi, vol. 28, no. 6, pp. 413-417, 2005.

[24] M. U. Dogar, N. N. Shah, S. Ishtiaq et al., "Hydroxychloroquine-induced restrictive cardiomyopathy: a case report," Postgraduate Medical Journal, vol. 94, no. 1109, pp. 185-186, 2018.

[25] L. Szabó, N. Szentandrássy, K. Kistamás et al., "Effects of tacrolimus on action potential configuration and transmembrane 
ion currents in canine ventricular cells," Naunyn-Schmiedeberg's Archives of Pharmacology, vol. 386, no. 3, pp. 239-246, 2013.

[26] S. M. Dehghani, M. Haghighat, M. H. Imanieh et al., "Tacrolimus related hypertrophic cardiomyopathy in liver transplant recipients," Archives of Iranian Medicine, vol. 13, no. 2, pp. 116-119, 2010.

[27] T. M. Jarzembowski, E. John, F. Panaro et al., "Reversal of tacrolimus-related hypertrophic obstructive cardiomyopathy 5 years after kidney transplant in a 6-year-old recipient," Pediatric Transplantation, vol. 9, no. 1, pp. 117-121, 2005.

[28] R. K. Chang, S. V. McDiarmid, J. C. Alejos, S. E. Drant, and T. S. Klitzner, "Echocardiographic findings of hypertrophic cardiomyopathy in children after orthotopic liver transplantation," Pediatric Transplantation, vol. 5, no. 3, pp. 187-191, 2001. 